\title{
O exercício da tutela na Educação Inclusiva
}

\section{The exercise of guardianship in Inclusive Education}

\author{
Rose Jardim Madureira de Araujo ${ }^{1}$ \\ Cláudio Kleina ${ }^{2}$ \\ Marcus Vinicius Faria de Araujo ${ }^{3}$
}

\section{Artigo \\ Original}

Original

Paper

Palavras-chave:

Inclusão

Opressão

LIBRAS

\section{Resumo}

O exercício da tutela na educação inclusiva é o tema do presente trabalho e está baseado nas políticas inclusivas no ensino de surdos, visando à capacitação deste no exercício de sua cidadania. O objetivo principal é o de explicitar a importância do conhecer e do aplicar a cultura surda como pré-requisito para a construção dos projetos político-pedagógicos das instituições de ensino em suas gestões inclusivas. A metodologia utilizada foi a de fazer um contraponto entre a cultura surda e as políticas educacionais de inclusão vigentes no Brasil. Para o desenvolvimento de tal abordagem foi feito um paralelo entre as duas faces da inclusão, a saber: a inclusão opressora e a inclusão libertadora. Concluise após a pesquisa feita, que as políticas educacionais de inclusão na realidade produzem uma aculturação do surdo porque desconsideram a sua cultura e seu potencial construtivo, inventivo e criativo, devido a um rótulo preconceituoso de deficiência. Por fim, o presente artigo apresenta sugestões que contribuam para a viabilização de uma educação construtiva, igualitária e, de fato, inclusiva.

\begin{abstract}
The exercise of guardianship in inclusive education is the theme of this work and is based on inclusive policies in education of the deaf, aiming to make him/her able to exercise his/her citizenship. The aim is to explain the importance of knowing and applying the deaf culture as a requirement to the construction of the political-pedagogical projects in the teaching institution inclusive administration. The methodology used aimed to make a comparison between the deaf culture and the educational politics of inclusion in Brazil. In order to develop such an approach a parallel between oppressive inclusion and liberty inclusion were made. The results of this research show that the inclusion educational politics in fact produce an acculturation of the deaf because they disregard their culture and their constructive, inventive and creative potential, due to a preconceived label of deficiency. Finally this paper presents suggestions that contribute to the viability of a constructive, equal, and, indeed, inclusive.
\end{abstract}

Key words:

Inclusion

Oppression

LIBRAS
Recebido em $04 / 2011$

Aprovado em $08 / 2011$

\footnotetext{
${ }^{1}$ Graduada em Pedagogia pelo Centro Universitário Geraldo Di Biase - UGB. Pós-Graduanda em Educação Inclusiva - LIBRAS pela Faculdade Educacional da Lapa - FAEL

${ }^{2}$ Graduado em Sistemas de Informação pela Sociedade Paranaense de Ensino e Informática. Pós-graduado em Formação de Tutores e Orientadores Acadêmicos em EAD pela Uninter. Pós-graduado em Desenvolvimento em Ambiente WEB pela PUC/PR. Mestre em Educação pela PUC/PR.

${ }^{3}$ Professor do Centro Universitário de Volta Redonda - UniFOA. Mestre em Planejamento Energético pela UFRJ, Pós-Graduado em Ensino
} Superior pelo UniFOA e Graduado em Engenharia Química pela UFF. 
como cidadãos. Precisamos acima de tudo nos importar com eles, conviver, incluí-los de fato

A Lei Magna do Brasil determina a igualdade para todos e assegura o direito de acesso à educação como dever do estado. Considerando que no ano de 2000, o Censo do IBGE e o INEP apresentaram que nas grandes cidades do Brasil, os surdos se organizam por meio de associações de surdos, tornou-se hipótese do presente trabalho aferir até que ponto as escolas e as pessoas que fazem parte delas estão comprometidas com o desenvolvimento de habilidades e competências visando à capacitação do surdo no exercício de sua cidadania e formação profissional.

O objetivo que emergiu a partir da hipótese despertada foi o de explicitar a importância do conhecer e do aplicar a cultura surda como pré-requisito para a construção dos projetos político-pedagógicos das instituições de ensino em suas gestões inclusivas.

A Língua Brasileira de Sinais - LIBRAS é uma das línguas faladas no Brasil com reconhecimento oficial do governo brasileiro pela Lei 10.436/2002. O reconhecimento da LIBRAS inicia um processo de consolidação de políticas educacionais inclusivas no Brasil, pois veio reforçar a identidade dos surdos, sua língua e seu jeito de perceber o mundo.

Como limite final é mostrado um diagnóstico sobre a efetividade dos projetos políticopedagógicos na construção do desenvolvimento e capacitação do surdo visando sua autoconfiança e formação profissional que irá permitir plenamente o exercício de sua cidadania.

Ao final do trabalho, percebe-se a existência de um gap entre o que a Lei estabelece e o que a prática obtém como resultado.

A metodologia utilizada foi a de fazer um contraponto entre a cultura surda e as políticas educacionais de inclusão vigentes no Brasil. Para o desenvolvimento de tal abordagem foi feito um paralelo entre as duas faces da inclusão, a saber: a inclusão opressora e a inclusão libertadora.

\section{Libras: Uma questão de Cultura}

Conhecer a história da cultura surda vai muito mais além do que reconhecer que existam leis que os amparam em seus direitos na sociedade, de forma que estes se sintam valorizados e indispensáveis. Nessa leitura, se faz necessário refletirmos sobre as diversas faces do universo da educação dos surdos ao longo de sua trajetória e questionar seus erros e seus acertos, suas conquistas e seus desafios. Surge então um questionamento do porquê da existência de uma política de inclusão tão difícil de ser operacionalizada na sala de aula, já que o surdo continua excluído.

\subsection{A Gênesis da Cultura Surda}

Ao longo da história, a educação de surdos evoluiu continuamente, apesar das turbulências, pois, apresentando sempre oportunidades e mudanças progressivas em alguns contextos educacionais, foi passando por caminhos estreitos e limitados pela cultura ouvinista. Haja vista a educação de surdos ser sempre determinada por sujeitos ouvintes, já que os surdos sempre foram minoria linguística, o foco central sempre girou em torno da língua. Isto é: Língua de Sinais ou Língua Oral?

\subsubsection{Uma cultura, dois olhares}

A cultura surda, em sua origem, pode ser percebida pelo menos sob dois olhares, a saber: o olhar histórico sob a cultura surda e o olhar do sujeito surdo frente à realidade do mundo oralista.

Sacks (1998, p.27) relata que foi no período compreendido entre 1712 e 1789, na França que surgiu pela primeira vez uma escola para crianças surdas, onde um esboço da cultura surda começou a se formar. O método de ensino dessa escola combinava a língua de sinais com a gramática francesa, culminando num acesso efetivo bem sucedido à educação dos surdos.

Tal método ficou conhecido como Método de L'Eppée em homenagem ao abade Michel de L'Eppée que foi mentor do início desse processo de educação inclusiva. A escola citada acabou por se transformar no Instituto Francês de Surdos. Posteriormente, no século XIX, nos Estados Unidos da América (EUA), segundo Strobel (2006), surgiu a língua de sinais americana (ASL) deveras influenciada pela língua 
francesa de sinais . Num movimento pioneiro, Thomas H. Gallaudet e Laurent Clerc fundaram a primeira escola para surdos nos EUA, a qual foi a base para a fundação da única Universidade para Surdo no mundo, hoje conhecida como Universidade de Gallaudet.

É importante ressaltar que no contexto histórico dos séculos XVIII e XIX qualquer tipo de deficiência era naturalmente associada a misticismo e ocultismo, conforme Mazzotta (1999, p.16) afirmou que "[...] até o século XVIII, as noções a respeito da deficiência eram basicamente ligadas a misticismo e a ocultismo, não havendo base científica para o desenvolvimento de noções realísticas".

As políticas educacionais para o surdo foram grandemente impulsionadas no final do século XIX, mais precisamente em 1880, com o advento ocorrido na cidade de Milão, na Itália, conhecido como I Congresso Internacional de Professores de Surdos. Naquela oportunidade, travou-se algo similar a um embate entre defensores do oralismo e os defensores das línguas de sinais. Sendo a grande maioria dos participantes defensores do oralismo, segundo Lacerda (1998, pp. 68-80), a única oposição significativa ao oralismo foi apresentada por Gallaudet, que, entretanto, não foi suficiente para evitar que o oralismo prevalecesse praticamente de 1880 até por volta de 1970 ( FILIETAZ, 2006, p.20). Os surdos foram condenados a abdicar de sua própria língua e forçados a adaptar-se a cultura ouvinte.

Em 1857, foi fundada, no Brasil, a primeira escola para surdos: O Instituto dos SurdosMudos, hoje, Instituto Nacional da Educação de Surdos (INES). Tal iniciativa decorreu do convite de Dom Pedro II ao professor Huet, formado no Instituto Francês de Surdo.

Soares (1999 apud FILIETAZ, 2006, p.21), relata que em 1896 o governo brasileiro enviou o professor do INES, A.J. de Moura e Silva, ao Instituto Francês de Surdos visando avaliar a metodologia oralista indicada no Congresso de Milão.

O resultado prático dessa avaliação foi adoção no Brasil do oralismo puro (OLIVEIRA, 2006 apud FILIETAZ, 2006, p.22). Isso não significou que o ensino de LIBRAS tenha sido banido, em sua íntegra, no Brasil, mas que tenha ficado em uma espécie de "estágio esporulado".
No decorrer do séc. XX, diversos estudos e experiências sobre linguagem, educação e surdez mostraram grandes brechas no método oralista, pois este acabava por reforçar que o surdo na verdade era um ouvinte deficiente. De certo modo era uma manifestação daquilo que M.Foucalt (1984, p.28) afirmou em sua obra intitulada Doença Mental e Psicologia: “É próprio à nossa cultura dar à doença o sentido do desvio e ao doente um status que o exclui".

Segundo Perlin (1997, p.56), ser surdo é pertencer a um mundo de experiência visual e não auditiva. Essa afirmativa parece ter sido inspirada na mobilização da comunidade surda, que ocorreu a partir de meados de 1960, cujo objeto era o reconhecimento do surdo como sujeito social.

\subsubsection{O olhar do sujeito surdo}

Certamente que uma criança não nasce surda-muda: elas são surdas ou ouvintes. Segundo a Secretaria de Educação Especial do MEC(Brasil, 2005), as competências e deficiências provenientes dos diferentes níveis de surdez incluem as seguintes características: surdez leve, surdez moderada, surdez severa e surdez profunda. Como surdez leve entende-se que a mesma ocorre quando a criança é capaz de perceber os sons da fala adquire e desenvolve linguagem oral espontaneamente e o problema geralmente é descoberto tardiamente. Dificilmente, nesse caso, há necessidade de uso de aparelho de amplificação, uma vez que a audição é próxima do nível considerado normal; Na surdez moderada, a criança pode apresentar algum atraso no desenvolvimento da fala e da linguagem; apresenta também alterações articulatórias (trocas na fala) por não perceber todos os sons com clareza, tem dificuldade em perceber a fala em ambientes ruidosos; apresentam desatenção e dificuldade no aprendizado da leitura e da escrita.

$\mathrm{Na}$ surdez severa, a criança apresenta dificuldade em adquirir a fala e a linguagem espontaneamente, podendo, porém, adquirir vocabulário próprio de seu contexto familiar e, por fim, a surdez profunda quando a criança dificilmente desenvolverá linguagem oral espontaneamente; responde auditivamente apenas a sons muitos intensos (vibrações). Apesar dos níveis de surdez, devemos observar a rea- 
lidade inicial do ser humano em suas primeiras experiências sociais.

Ao chorar, o bebê prova que tem cordas vocais; ou seja, ele emite sons. Na medida em que vai desenvolvendo seu relacionamento com os pais, vai observando e respondendo aos estímulos recebidos. Mas se não puder ouvir a voz que o estimula não haverá resposta de aprendizado oral, pois não pode imitar algo que não foi percebido. Por isso não fala. Já uma criança ouvinte vai reproduzir o que ouviu. Para ilustrar melhor o dilema enfrentado pelo sujeito surdo ,na construção da sua identidade, citamos um exemplo dado por Santana, Bergamo (2005 apud FAEL, apostila de Cultura Surda, 2010, p.3).

Paula: // escreve " pensei que eu era a única surda no mundo"// porque ouvinte fala. Eu olhava para a sua boca e não compreendia. Não sabia por que eu não podia falar. Ficava decepcionada // escreve "decepcionada"// Tentei descobrir por que eu não podia falar (...) Surdo nasce. A mãe ensina a falar, a estudar. Não sabe sinais. Não pode fazer sinais. Fazer sinais implica ser acomodado e não falar. Assim, ele cresce sem conhecer sinais sem nunca ter encontrado outro surdo. Um dia, ele vai passando pela rua e encontra um surdo fazendo sinais. Ele olha para os movimentos das mãos e estranha. Pergunta ao surdo: "você não ouve?". "Não. Sou surdo. Todos aqui são." "Eu também sou. Eu não escuto. Eu só falo. "Vê os sinais e pergunta: "O que é isso? Eu não sei. Eu queria aprender". Ele começa a aprender língua de sinais. Depois, em casa, com a família, não se sente bem em falar. Quer aprender a língua de sinais. Como podemos ver é imprescindível o envolvimento dos pais na identidade cultural de seus filhos, a família, a escola, as instituições, todos devem se incluir na cultura do outro para haver troca de experimentações e aprendizagem.

Daí a importância de famílias de surdos que possuam cultura ouvinte perceberem, o mais rápido possível, a surdez, respeitando a possibilidade de comunicação do filho com outra cultura, a saber: a cultura surda. Além disso, é mister introduzir o filho surdo na comunidade surda local o quanto antes, bem como os próprios familiares participarem dessa comunidade de modo a fortalecer vínculos familiares e libertarem-se de preconceitos.

\subsection{Língua e Identidade Surda}

A linguagem é essencial para a construção da identidade, pois é através dela que o homem se percebe e percebe o outro. A leitura do sujeito em suas percepções do mundo processa e fundamenta sua cultura. Assim, uma criança surda precisa se integrar o mais rápido possível à Comunidade Surda de sua cidade para poder ficar com um bom desempenho na língua de sinais dessa comunidade. Isso facilitará a compreensão da outra língua em sua modalidade escrita e quando possível na sua modalidade falada. É mister então que seja dada à criança surda, a possibilidade plena de interação social, alicerçada no fortalecimento de sua identidade surda. Sendo assim, a Libras é a ferramenta essencial para o bom desempenho das atividades do sujeito surdo.

Existe um mito de que as línguas de sinais são somente um conjunto de gestos que interpretam as línguas orais. Assim como existe também o mito de que as línguas de sinais são iguais em todo o mundo, o que não é verdade, pois as pessoas surdas de cada parte do mundo têm sua língua de sinais, assim como a língua oral. Os usuários de qualquer língua podem expressar seus pensamentos de formas variadas, assim, a pessoa que fala uma determinada língua utilizaa de acordo com o contexto, portanto, o modo de se falar com seus amigos não é o mesmo de falar com estranhos. Todas as línguas possuem diferenças quanto ao seu uso em relação ao grupo social, ao gênero e a idade. A língua de sinais, embora seja de modalidade diferente (gestual visual) também possui essas características em sua estrutura, porque elas também são compostas pelos níveis descritos acima.

Uma peculiaridade da língua de sinais é que embora ela seja diferente da língua de sinais de outro país, os surdos têm maior facilidade em comunicar-se com os surdos de outros países, fato que não acontece entre os falantes de línguas orais,os quais necessitam de um tempo bem maior para o entendimento. 
O fato de os surdos terem habilidades e competências para o desenvolvimento e o aproveitamento de gestos, bem como a sensibilidade e percepção das expressões faciais e corporais das pessoas, faz com que a aprendizagem seja de fácil entendimento. Quando uma pessoa aprende uma língua, apreende também os hábitos culturais e os contextos aos quais certas expressões estão vinculadas. Os comportamentos das pessoas, diante de eventos diversos, produzem diferentes modalidades comunicativas.

Segundo a linguista surda Carol Padden (1989, p.5) existe uma diferença entre cultura e comunidade. Para ela, " uma cultura é um conjunto de comportamentos aprendidos de um grupo de pessoas que possuem sua própria língua, valores, regras de comportamento e tradições". Ao passo que " uma comunidade é um sistema social geral, no qual as pessoas vivem juntas, compartilham metas comuns e partilham certas responsabilidades umas com as outras". Acrescente-se a esse fato, ser necessário, a observância na dimensão espacial, isto é: a forma de ocupação de um grupo de pessoas, via de regra, faz com que comecem a emergir objetivos comuns e consequentemente, estratégias comuns para o alcance de tais objetivos.

Em uma comunidade surda é possível a interação e a presença de ouvintes. Dessa possibilidade surgem expectativas promissoras em relação ao compartilhamento de culturas e metas comuns de seus membros. Sendo assim, é possível inferir que uma comunidade surda seja mais aberta para o novo do que a cultura surda. Obviamente que ser uma pessoa surda não quer dizer que esta faça parte de uma cultura e de uma comunidade surda. Isso ocorre devido ao fato de que a maioria dos surdos, descendentes de ouvintes, em sua maioria, não aprendem sua língua e não convivem com outros surdos nas associações de surdos. Por conseguinte, formata-se aí uma crise de identidade em que o surdo recebe o rótulo de "deficiente auditivo".

O termo deficiente atribui ao surdo um jeito de ser, de ver e perceber o mundo de forma incompleta e inaceitável aos olhos de uma outra cultura: a cultura ouvinte. Estabelecese, desse modo, a encarnação de uma pedagogia opressora, que pretende eternizar o domínio sobre as minorias, mutatis mutantis, o sistema de castas existentes em algumas culturas do mundo.

\section{As Faces da Inclusão}

O termo inclusão tem sua origem na expressão inglesa “full inclusion" e implica, portanto, em algo pleno, completo. Não é possível pensar em inclusão e praticá-la de forma incompleta. Sendo assim, a inclusão deve ser vista seja através de sua face legal, seja através de sua face operacional. Entenda-se como face legal o conjunto de instrumentos regulatórios que doutrinam o sistema de educação especial; como face operacional, a prática daquilo que está estabelecido na legislação.

\subsection{A Face Legal}

Devido à tendência natural do homem a excluir tudo aquilo que não compreende, a inclusão social necessitou de adaptações legais em seus diversos níveis a fim de nortear todo processo construtivo. Desse modo, na esfera internacional, surgiu, em 1948, a Declaração Universal dos Direitos Humanos, que fundamentalmente apregoa que todos somos iguais perante a Lei sem distinção, possuindo os mesmos direitos inclusive o da instrução.

A Declaração de Salamanca, em 1994, na Espanha, é outro instrumento norteador em âmbito internacional, constituindo-se em um dos mais importantes compromissos em relação a direitos educacionais. Em tal documento, encontramos a declaração de que as escolas regulares inclusivas seriam o meio mais eficaz de combater a exclusão de crianças cujas características diferem daquelas consideradas normais. No âmbito nacional, em 1988, temos a Constituição Federal Brasileira que em seu artigo $208 \mathrm{diz}$ :

O dever do Estado com a educação será efetivado mediante a garantia de:

I - ensino fundamental obrigatório e gratuito, assegurada, inclusive, sua oferta gratuita para todos os que a ele não tiveram acesso na idade própria;

II - progressiva universalização do ensino médio gratuito;

III - atendimento educacional especializado aos portadores de deficiência, preferencialmente na rede regular de ensino;

IV - atendimento em creche e pré-es- 
cola às crianças de zero a seis anos de idade;

V - acesso aos níveis mais elevados de ensino, da pesquisa e da criação artística, segundo a capacidade de cada um; V1 - oferta de ensino noturno regular adequado às condições do educando;

VII - atendimento ao educando no ensino fundamental através de programas suplementares de material didáticoescolar, transporte, alimentação e assistência à saúde.

$\S 1^{\circ} \mathrm{O}$ acesso ao ensino obrigatório e gratuito é direito público subjetivo;

$\S 2^{\circ} \mathrm{O}$ não-oferecimento do ensinoobrigatório pelo Poder Público, ou sua oferta irregular importa responsabilidade da autoridade competente;

$\S 3^{\circ}$ Compete ao Poder Público recensear os educandos no ensino fundamental, fazer lhes a chamada e zelar, junto aos pais ou responsáveis, pela frequência à escola.

Outro instrumento normativo de âmbito nacional é a Lei de Diretrizes e Bases da Educação - LDBN, que, através da lei 9394/96, determinou que a educação especial, sendo uma modalidade de educação, deve ser oferecida, preferencialmente, na rede regular de ensino aos alunos com necessidades educacionais especiais.

\subsection{A Face Operacional}

Nesse momento de transição metodológica que é sugerido por uma pedagogia inclusiva surge a necessidade de conhecer a cultura do povo surdo, suas aspirações, suas metas sua diferença cultural e linguística.

Skutnabb-Kangas (1994, p.152) apresenta os direitos humanos linguísticos:

Todos os seres humanos têm direito de identificarem-se com uma língua materna e de serem aceitos e respeitados por isso.

Todos têm o direito de aprender a língua materna completamente, nas suas formas oral (quando fisiologicamente possível) e escrita (pressupondo que a minoria linguística seja educada na sua língua materna).

Todos têm o direito de usar sua língua materna em todas as situações oficiais (inclusive na escola);

Qualquer mudança que ocorra na língua materna deve ser voluntária e nunca imposta.

A LIBRAS é a língua de sinais natural dos surdos brasileiros com estruturas gramaticais necessárias e é reconhecida pela linguística. Pesquisas já comprovaram que quanto mais cedo o surdo entrar em contato com sua língua natural - a LIBRAS - mais eficaz e facilitada será sua integração na sociedade. Segundo o IBGE (Censo de 2000), para cada 100 mil homens em 2000, 103,4 eram surdos, enquanto entre as mulheres a relação era de 92,7. Em 1991, esses valores correspondiam a 125,1 e 111,5, respectivamente. A incidência da surdez em 2000 era mais comum nos estados de Piauí, Paraíba, Pernambuco e Sergipe (Nordeste), no Tocantins (Norte) e em Goiás (Centro-Oeste).

É notório que a presença da comunidade surda no Brasil é mais concentrada nos grandes centros onde os surdos se organizam por meio das associações onde se estabelecem os vínculos culturais.

A face operacional nos mostra que devemos olhar a inclusão e reconhecer que, ao se pensar em incluir o outro, é fundamental estar disposto a se incluir na realidade da cultura surda para haver o processo de troca, gerador de aprendizagem efetiva. Desse modo, a face operacional da inclusão pode ser vista por dois lados distintos, como se fora uma moeda; de um lado da moeda, se apresenta uma inclusão opressora, e de outro lado da mesma moeda, uma inclusão libertadora, conforme podemos observar na figura 1 .

Figura 1: Os olhares para a inclusão.

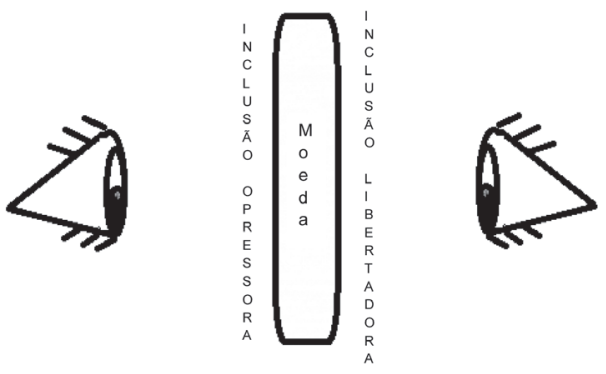

Fonte: Ilustração proposta por ARAUJO, Rose J. M. de, 2011. 
Percebe-se assim que uma política educacional inclusiva necessita ser verificada, avaliada periodicamente de modo a sofrer ajustes que corrijam eventuais distorções que somente aparecem no transcorrer da face operacional.

A existência de dois olhares diametralmente opostos para o mesmo desafio, que é a inclusão do sujeito surdo, demonstra que ações corretivas tutoriais devem ser tomadas de modo a fazer com que a inclusão opressora seja devidamente banida e dê lugar à inclusão libertadora, construída sobre os dois fundamentos, a saber: a cultura surda e a cultura ouvinte.

\subsubsection{A inclusão opressora}

Chamamos aqui de inclusão opressora àquela em que sugere que o surdo deve migrar para outra cultura que não é de sua natureza linguística. Sobre a questão da opressão Freire (1996, p.67) disse:

"O respeito à autonomia e à dignidade de cada um é um imperativo ético e não um favor que podemos ou não conceder uns aos outros. (...) É nesse sentido também que a dialogicidade verdadeira, em que os sujeitos dialógicos aprendem e crescem na diferença, sobretudo, no respeito a ela, é a forma de estar sendo coerentemente exigida por seres que, inacabados, assumindo-se como tais, se tornam radicalmente éticos. É preciso deixar claro que a transgressão da eticidade jamais pode ser vista como virtude, mas como ruptura com a decência. O que quero dizer é o seguinte: que alguém se torne machista, racista, classista, sei lá o quê, mas se assuma como transgressor da natureza humana. Não me venha com justificativas genéticas, sociológicas ou históricas ou filosóficas para explicar a superioridade da branquitude sobre a negritude, dos homens sobre as mulheres, dos patrões sobre os empregados. Qualquer discriminação é imoral e lutar contra ela é um dever por mais que se reconheça a força dos condicionamentos a enfrentar."

Desse modo, é preciso transgredir esse processo opressor que inclui o surdo na es- cola para o excluir em sala de aula, gerando sentimentos de menos valia, desprezando e considerando a identidade surda inferior à identidade ouvinte. Segundo Perlin (1998, apud APOSTILA DE CULTURA SURDA DA FAEL, 2010, p. 1) os defensores da língua de sinais para os surdos afirmam que é só de posse desta, considerada "natural", adquirida em qualquer idade, que o surdo construirá uma identidade surda, já que ele não é ouvinte.

\subsubsection{A Inclusão libertadora}

O verso da moeda ao qual chamamos de inclusão libertadora está fundamentado no fato de o sujeito surdo, assim como o sujeito ouvinte, poder se expressar com confiança em sua própria identidade, por meio de uma comunhão com outras línguas. Essa comunhão com outras línguas pode ser vista como uma forma de libertação do modelo de inclusão existente, apresentando um sentido construtivista e interacional, conforme propuseram Piaget em 1998 e Vigotsky em 2005.

A inclusão libertadora, portanto, oportuniza a emancipação do sujeito surdo ante a opressão de um sistema inclusivo raso e embaçado. Tal emancipação se dá na migração da teoria legal para a intervenção prática no cotidiano de sala de aula.

Fonseca (2007) afirma que a proposta de Paulo Freire sempre foi pautada nas experiências do ambiente extra escolar de cada aluno, como forma de estimular novas práticas educacionais. Bello(1993) afirmou que para Paulo Freire, o diálogo seria o elemento chave para acionar a efetiva troca entre professor e aluno. Esse diálogo, quando consideramos a relação surdo-ouvinte pode ser expresso como a necessidade do bilinguismo. Para a realização da inclusão libertadora, é necessário então que as políticas educacionais e inclusivas admitam a necessidade de amalgamar a cultura ouvinte à cultura surda. Sobre isso trataremos no próximo capítulo.

\section{Políticas Públicas para a Educação Inclusiva}

O estabelecimento de políticas públicas para a educação inclusiva sinaliza 
para o reconhecimento da necessidade de se tutelar o sujeito surdo de modo a, verdadeiramente, inseri-lo na sociedade. Nesse capítulo, discutiremos a efetividade das políticas públicas para a educação inclusiva, abordando a evidente defasagem entre recursos humanos capacitados para facilitar a construção educativa e as adaptações curriculares necessárias à sustentação educacional do sujeito tutelado.

Segundo Frey (2000, pp. 232-233) o termo política pública é uma referência direta ao conjunto de leis, regulamentos, diretrizes, planos, orçamentos e demais decisões originadas no seio do poder público, tendo em vista o alcance da satisfação das demandas sociais.

A gestão escolar pautada nessas diretrizes tem obrigação de valorizar a língua de sinais em seus currículos, proporcionando ofertar ao surdo, métodos de ensino de natureza visual e espacial em que o oralismo é substituído pelo letramento bilíngue. É importante ressaltar que as políticas públicas voltadas para a educação, notadamente a educação inclusiva, precisa considerar as diferentes realidades de um país de dimensões continentais como o Brasil. Somos um povo com alto nível de miscigenação com grandes diversidades culturais em todas as regiões do Brasil. Além disso, as políticas públicas devem considerar a defasagem entre recursos humanos capacitados para facilitar a construção educativa e adaptações curriculares.

Quanto à inclusão em sala de aula, a obra "Bilinguismo" (FAEL, 2010, p. 4) cita que:

"Com a percepção dos estudiosos acerca do ensino para surdos, surgiram, paulatinamente, pontos de vista mais coerentes com a realidade dos alunos surdos. Passou-se a reconhecer que o mais correto é que o ensino seja oferecido por meio de uma linguagem visual-espacial (língua de sinais). É sabido que as escolas devem desenvolver esta metodologia de ensino em turmas homogêneas, para que os alunos possam estar no mesmo grau de aprendizado, enfrentando as mesmas situações e aprendendo a vencê-las. Em contrapartida, a heterogeneidade (surdos e ouvintes) nas turmas faz com que o surdo não acompanhe a maioria ouvinte, ficando sempre para trás e se auto julgando impotente diante das adversidades encontradas em seu caminho. Para que essa realidade seja mudada, é importante que os professores dominem a Libras, pois assim, terão trabalho e relação escolar efetiva com seus alunos."

Figura 2: Cobertura das Políticas Públicas ao sujeito tutelado.

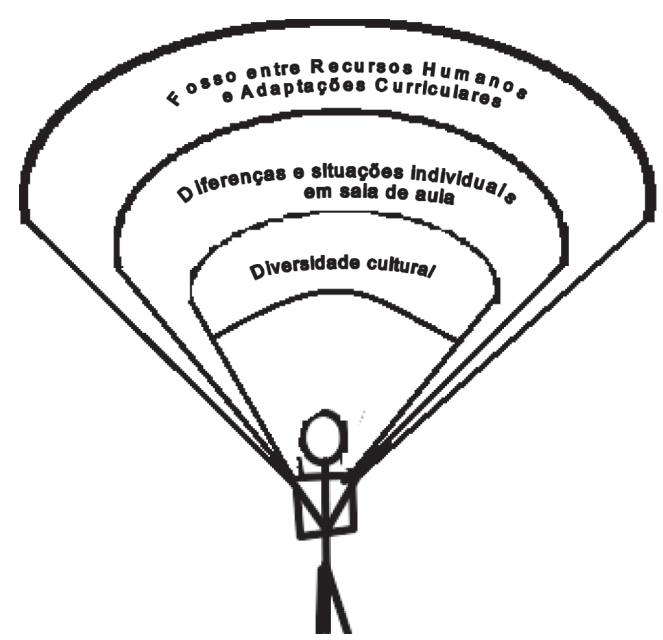

Fonte: Ilustração proposta por ARAUJO, Rose J. M. de, 2011.

Um exemplo de sucesso na prática inclusiva, relatado por QUADROS (2006, pp. 154155), ocorria no Estado de Santa Catarina, o qual contratava professores de Libras para atuarem nas escolas. Os depoimentos dos alunos em relação à presença do professor surdo eram de muita satisfação. A própria professora reconhecia o valor desse momento, pois observava o quanto os alunos desfrutavam da relação com esse professor. A prática, entretanto, verificou que, sendo poucos os instrutores e/ ou professores surdos contratados para aquela tarefa, eles acabavam reduzindo o seu envolvimento com cada grupo. Dessa forma, continuava-se a limitar o acesso dos alunos ao conhecimento em língua de sinais, pois o tempo era tão escasso para esta experiência que o professor ou interprete dominava tão pouco a língua, que o aluno continuava a não ter modelos linguísticos adequados, comprometendo, com isto, o seu processo de aquisição. Além disso, esse mesmo instrutor/professor teria a função de preparar o professor e o intérprete 
de língua de sinais, bem como ministrar os cursos para familiares.

Nos cursos de capacitação de língua de sinais, todos os professores e intérpretes tiveram a oportunidade de ter contato com instrutores surdos, mas estamos referindo, aqui, o trabalho sistemático que envolve a periodicidade no próprio ambiente escolar. Esse esforço estaria previsto, mas não foram contratados os instrutores ou professores surdos para assumir essas funções (QUADROS, 2006, p. 155). Veja que não houve inclusão de professores nem funcionários surdos no ambiente escolar. Isso viria reforçar a autoestima do sujeito surdo, bem como possibilitar a inclusão de outros surdos na sociedade, e ainda, iria oportunizar aos ouvintes o conhecimento e aquisição de uma nova experiência social e inclusiva. O professor de língua de sinais assume o papel do integrador nas escolas, com a tarefa de orientar os professores e a comunidade escolar quanto à língua de sinais e às formas de ensinar e aprender dos alunos surdos. É uma tarefa que está relacionada diretamente com os próprios surdos.

Assim, os professores surdos, formados nas áreas específicas, conseguem passar as experiências visuais de uma forma diferenciada. O fato de ser surdo já traz uma vivência das relações com surdos para alunos de ambos os contextos.

Stainback \& Stainback (1999, pp. 22-31) afirma que a política de inclusão educativa embora seja um vetor para o ensino de alunos deficientes, a efetiva implantação da mesma no Brasil ainda carece de muitos avanços. Concordamos com o disposto em BRASIL (2006 c, p.29) que diz:

Políticas educacionais deveriam levar em total consideração as diferenças e situações individuais. A importância da linguagem de signos como meio de comunicação entre os surdos, por exemplo, deveria ser reconhecida e provisão deveria ser feita no sentido de garantir que todas as pessoas surdas tenham acesso a educação em sua língua nacional de signos. Devido às necessidades particulares de comunicação dos surdos e das pessoas surdas/cegas, a educação deles pode ser mais adequadamente provida em escolas especiais ou classes especiais e unidades em escolas regulares. (BRASIL, 2006c, p. 29).

Visando exemplificar o alcance que a política pública inclusiva tem permitido, tomemos como o exemplo alguns programas televisivos diversos que, ao iniciarem sua programação, informam a censura em Libras e ao longo de seu conteúdo nada mais é traduzido para os surdos. Outro exemplo que podemos levantar é o fato que muitas vezes o intérprete fica sem ter como atuar em competências de ordem pedagógicas que não são suas.

Existem vários problemas que surgem em sala de aula que não caberia na função do intérprete, tais como: apresentar informações pedagógicas a respeito do desenvolvimento do aluno, realizar atividade extraclasse, acompanhar e disciplinar os alunos. Essas práticas acabam reforçando a exclusão, uma sala dividida, em que se apresenta um "professor - intérprete", que dá sua aula para os surdos (minoria) independente do outro professor que dá sua aula para os ouvintes (maioria), criando dois grupos que não interagem entre si.

\subsection{A Tutela do Estado}

As políticas públicas educacionais e inclusivas no Brasil estão amparadas em pelo menos dois grandes pilares, a saber: o Decreto $\mathrm{n}^{\circ} 5.626$, de 22 de dezembro de 2005 e a Lei ${ }^{\circ}$ 12.319 de $1^{\circ}$ de setembro de 2010 .

O Decreto $n^{\circ} 5.626$, de 22 de dezembro de 2005 regulamenta a Lei no 10.436 , de 24 de abril de 2002, que reconhece a Libras como meio legal de comunicação e estabelece, entre outras coisas, a obrigação de o poder público tutelar a formação de intérpretes de língua de sinais.

Já a Lei $n^{\circ} 12.319$, de $1^{\circ}$ de setembro de 2010, regulamenta a profissão de tradutor e intérprete da língua brasileira de sinais - Libras.

Essa tem sido então a base da tutela do Estado para promover a inclusão do sujeito surdo na escola regular. Essa é, sem dúvida, uma iniciativa louvável do ponto de vista estrutural, pois valoriza a função do profissional intérprete de língua de sinais. Sem esse reconhecimento instalava-se um remendo onde o intérprete funcionava desvinculado da instituição de ensino e, por conseguinte, dos projetos político peda- 
gógicos das instituições onde era solicitado. Isso demonstrava que o compromisso prático das escolas visava mais o cumprimento da lei do que viabilizar as necessidades específicas dos alunos surdos. A partir da Lei ${ }^{\circ} 12.319$ de $1^{\circ}$ de setembro de 2010, oportuniza-se a admissão desses profissionais, possibilitando o alcance da prática inclusiva. Isso se dá devido à forma mais prática e eficiente de oportunizar ao intérprete conviver com os demais docentes proporcionando uma genuína interdisciplinaridade, dando maior chance de sucesso ao projeto político pedagógico da escola.

Entretanto bias ocorrem na execução dessa tutela devido ao fato do sujeito surdo continuar a ser rotulado como deficiente, desconsiderando a existência de sua cultura. Tal prática fomenta uma insustentabilidade inclusiva revelando um perverso sistema educacional opressor que, em tese, considera iguais todos os indivíduos, mas na prática ele reforça a desigualdade.

\subsection{Adaptações curriculares no contex- to Da Tutela}

Freire (1987) afirma que a violência dos opressores, que os faz desumanizados, não instaura outra vocação: a do ser menos. Isto é: quando a práxis da tutela da educação inclusiva pretende que se alcance "o ser mais", promovendo o sujeito surdo a patamares superiores pelo acesso comum aos conteúdos curriculares; na realidade essa mesma práxis, de forma perversa, impõe aos sujeitos surdos a sensação de "ser menos", que mais cedo ou mais tarde, os incentivará a se rebelarem contra quem os fez menos.

A adaptação curricular deve expressar a necessidade de confluência das culturas ouvinte e surda e não se materializar como uma benesse ao deficiente. Tal confluência deve respeitar e possuir simetria para fazer com que o sujeito ouvinte interaja com a cultura surda e o sujeito surdo interaja com a cultura ouvinte. Assim sendo, certamente alcançaremos um tipo de cultura elevada, epistêmica e ética tanta intratemporal quanto intertemporalmente.

\section{Considerações Finais}

É notória a necessidade de uma reforma nas políticas públicas de educação inclusiva, que passem a limpo os projetos político-pedagógicos das instituições de ensino, de modo a introduzir novos paradigmas para o exercício da tutela da educação inclusiva. Ao longo da avaliação da trajetória histórica da educação inclusiva, foi possível perceber que as oportunidades de desenvolvimento cognitivo do sujeito surdo sempre estiveram na dependência da ditadura da cultura ouvinte. A desconsideração da relevância da cultura surda é perversa e opressora, estabelecendo assim, uma ordem em que o potencial construtivo, inventivo e criativo do surdo é sufocado por um tipo de pedagogia bancária, a qual parece se importar muito mais com estatísticas do que resultados práticos.

$\mathrm{O}$ rótulo preconceituoso de deficiência, então, precisa ser revisto, transformado por meio de ações conjuntas entre as duas culturas: ouvinte e surda. Nesse sentido, é importante ressaltar que tais ações não devem ser apenas uma sobreposição de valores, mas uma sinergia de culturas.

Com vistas a contribuir para a viabilização de uma educação verdadeiramente construtiva, igualitária e, de fato, inclusiva, sugerese que a cultura surda passe a fazer parte do interesse da cultura ouvinte. Obviamente, que as autoridades competentes precisam agir desenvolvendo planos e programas que fomentem o interesse dos ouvintes para esta cultura oprimida e oculta. É claro que tais planos e programas deverão suceder a formulação de políticas públicas educacionais inclusivas calcadas numa concepção problematizadora e participativa em que o povo surdo seja ouvido e inserido nesse processo libertador de construção social. 


\section{Referências}

1. BELLO, José L P. de.. E uma nova filosofia para a educação (1993). Disponível em: http://www.pedagogiaemfoco.pro.br/ per01.htm. Acesso em 14.02.2011.

2. BRASIL. Constituição (1988). Constituição da República Federativa do Brasil: promulgada em cinco de outubro de 1988. Contém as emendas constitucionais posteriores. Brasília, DF: Senado, 1988.

3. BRASIL. Lei de Diretrizes e Bases da Educação Nacional. Lei $n^{\circ}$ 9394, de 20 de dezembro de 1996.

4. BRASIL/MEC - Ministério da Educação. Lei n. ${ }^{\circ} 10.436$ de 24 de abril de 2002. Disponível em http://portal.mec.gov.br/ seesp/arquivos/pdf/lei10436.pdf. Acesso em 03.02.2011.

5. BRASIL/MEC - Ministério da Educação. Lei n. ${ }^{\circ} 5.626$ de 22 de dezembro de 2005. Disponível em http://www. planalto.gov.br/ccivil_03/_ato20042006/2005/decreto/d5626.htm. Acesso em 14.02.2011.

6. BRASIL/MEC - Ministério da Educação. Lei n. $^{\circ} 12.319$ de $1^{\circ}$ de setembro de 2010. Disponível em http://www.planalto. gov.br/ccivil_03/_Ato2007-2010/2010/ Lei/L12319.htm. Acesso em 14.02.2011.

7. BRASIL. Secretaria deEducaçãoEspecial/ Ministério da Educação e Cultura.

8. Saberes e práticas da inclusão: desenvolvendo competências para o atendimento às necessidades educacionais especiais de alunos surdos. Brasília: SEESP/MEC, 2005.

9. Exame Prolibras / Ronice Müllerde Quadros... [etal.]. Florianópolis, 2009.
10. FILIETAZ, Marta R. P.. Políticas públicas de educação inclusiva: das normas à qualidade de formação do intérprete de língua de sinais. 2006. Curitiba. Dissertação (Mestrado em Educação). Programa de Pós-Graduação em Educação/Mestrado em Educação, na Linha de Pesquisa de Políticas Públicas da Universidade Tuiuti do Paraná.

11. FONSECA, Valter M.(2007). Paulo Freire e a educação libertadora, Disponível em : http://www.destaquein.sacrahome.net/ node/348. Acesso em 14.02.2011.

12. Foucault, M. (1984a). Doença Mental e Psicologia (L. Shalders, Trad.). Rio de Janeiro: Tempo Brasileiro.

13. FREIRE, Paulo. Pedagogia da autonomia: saberes necessários à prática educativa. 13. ed.. Rio de Janeiro: Paz e Terra, 1996.

14. FREIRE, Paulo. Pedagogia do oprimido. 17. ed.. Disponível em: http://portal. mda.gov.br/portal/saf/arquivos/view/ ater/livros/Pedagogia_do_Oprimido.pdf. Acesso em 14.02.2011.

15. FREY, Klaus. Políticas públicas: um debate conceitual e reflexões referentes à prática da análise de políticas públicas no Brasil. Planejamento e Políticas Públicas. $n^{\circ}$. 21. jun/2000.

16. LACERDA, Cristina B.F. de. Um pouco da história das diferentes abordagens na educação dos surdos. Cad. CEDES [on line]. 1998, v.19, n.46, pp. 68-80. Disponível em http://www.scielo.br/ scielo.php?script $=$ sci_arttext\&pid=S0101$32621998000300007 \& \operatorname{lng}=$ pt\&nrm=iso. Acesso em 06.03.2011.

17. MAZZOTTA, Marcos José da Silveira. Educação especial no Brasil: história e políticas públicas. 2 ed. São Paulo: Cortez, 1999. 
18. OliveIRA, Paulo M. T. de. História da educação dos surdos no Brasil. Disponívelemhttp://www.lagoinha. org.br/ephata/ph pw cms/index . php?id=2,9,0,0,. Acesso em 02.02.2011.

19. PERLIN, Gladis.T.; QUADROS, Ronice Müller.. Educação de surdos em escola inclusiva? Revista Espaço, vol. 7. Rio de Janeiro: Ines, 1997.

20. PIAGET, J. A psicologia da criança. Ed Rio de Janeiro: Bertrand Brasil, 1998.

21. QUADROS, R M de. Políticas lingüísticas e educação de surdos em Santa Catarina: Cruz do Sul: EDUNISC, 2006. Espaço de negociações. Cad. CEDES, maio/ago. 2006, vol.26, nº69.

22. SACKS, Oliver. Vendo vozes: uma jornada pelo mundo dos surdos. Trad. Laura Teixeira Motta. São Paulo: Companhia das Letras, 1998.

23. SANTANA, Bergamo (2005). Apostila de Cultura Surda (FAEL). Paraná. 2010.

24. SKUTNABB-KANGAS, Tove. Lingüística Direitos Humanos. Um prérequisito para Bilingüismo. Ahlgren \& K. Hyltenstam (eds.) Bilinguismo em Surdos Da Educação. Estudo Internacional sobre Língua de Sinais e Comunicação dos Surdos. Vol. 27. Hamburgo: Signum-Verl, 1994.

25. SOARES, Maria A. L.. A educação do surdo no Brasil. Campinas/SP: Autores Associados, 1999.

26. STAINBACK, Susan.; STAINBACK, William. (Orgs.) Inclusão: um guia para educadores. Porto Alegre: Artmed, 1999.

27. STROBEL, Karin Lílian. A tradicional história de educação de surdos. Disponível em www.surdospelsurdos.com/ noticiaseducacao.asp. Acesso em 02.02.2011.

28. VYGOTSKY, L.S. Pensamento e linguagem. Tradução: Jefferson Luiz Camargo. 3. ed. São Paulo: Martins Fontes, 2005.

Endereço para Correspondência:

Marcus Vinicius Faria de Araujo marcus.araujo@foa.org.br Rua 18-B, n 43, sala 104, Vila Santa Cecília - Volta Redonda - RJ CEP: $27260-100$. 